\title{
AVALIAÇÃO DE COMPOSTOS FUNCIONAIS E ATIVIDADE ANTIOXIDANTE EM FARINHAS DE POLPA DE GOIABAS ${ }^{1}$
}

\author{
JULIANA MESQUITA FREIRE 2 , CELESTE MARIA PATTO DE ABREU ${ }^{3}$, \\ ANGELITA DUARTE CORRÊA ${ }^{3}$, ANDERSON ASSAID SIMÃO ${ }^{4}$, \\ CLÁUDIA MENDES DOS SANTOS ${ }^{5}$
}

RESUMO-A goiabeira (Psidium guajava) é uma planta nativa brasileira, e seus frutos são ricos em compostos antioxidantes os quais podem causar a oxidação das lipoproteínas, reduzindo o estresse oxidativo. Objetivou-se com este trabalho determinar essas substâncias e a atividade antioxidante das farinhas dos frutos das cultivares Pedro Sato, Paluma e Século XXI. Foram selecionados 35 frutos de cada cultivar, levando-se em consideração o grau de maturação. Os frutos foram lavados, picados, congelados em nitrogênio líquido e liofilizados. Posteriormente, foram trituradas para a obtenção das farinhas. Os parâmetros analisados foram o teor de compostos fenólicos, vitamina $\mathrm{C}$, betacaroteno, fibras alimentares, minerais (ferro, potássio, cobre, magnésio, manganês, zinco e cálcio) e atividade antioxidante, pelos métodos DPPH e betacaroteno/ ácido linoleico. Os teores de compostos fenólicos foram maiores para a cultivar Século XXI. O teor de betacaroteno e fibra alimentar não variaram entre as cultivares analisadas. As cultivares Século XXI e Paluma destacaram- se na atividade antioxidante pelos dois métodos. Em relação aos minerais, não houve diferença significativa para o potássio, cobre e zinco. O mineral cálcio não foi detectado pelo método empregado. Os teores de ferro, magnésio e manganês foram maiores para as cultivares Paluma, Pedro Sato e Século XXI, respectivamente.

Termos para a indexação: goiaba, antioxidantes e minerais.

\section{EVALUATION OF FUNCTIONAL COMPOUNDS AND ANTIOXIDANT ACTIVITY IN GUAVA PULP FLOUR}

\begin{abstract}
Guava (Psidium guajava) is a native Brazilian plant and its fruits are rich in antioxidants compounds which can inhibit the liproteins oxidation, reducing the aggravations of oxidative stress. The objective of this study was to determine these substances and antioxidant activity of the flours from the fruits of Pedro Sato, Paluma and Século XXI cultivars. The parameters analyzed were phenolic compounds, vitamin $\mathrm{C}$, beta-carotene, dietary fiber, minerals (iron, potassium, copper, magnesium, manganese, zinc and calcium) and antioxidant activity by DPPH methods and beta-carotene/acid linoleic. The levels of phenolic compounds were higher for the Século XXI cultivar.The level of beta-carotene and dietary fiber did not vary among cultivars analyzed. The Paluma and Século XXI cultivars stood out in antioxidant activity by both methods. Regarding to minerals, there was no significant difference for potassium, copper and zinc. Calcium was not detected by the used method. Iron, magnesium and manganese were higher for Paluma, Pedro Sato and Século XXI, respectively.
\end{abstract}

Index terms: fruits, cultivars, bioactive substances.

\footnotetext{
${ }^{1}$ (Trabalho 218-11). Recebido em: 29-08-2011. Aceito para publicação em: 23-08-2012.

2Doutora em Agroquímica/Universidade Federal de Lavras-MG. E-mail: mesquitafreire@yahoo.com.br

3Professora Associada do Departamento de Química da Universidade Federal de Lavras-MG. Emails: celeste@ufla.br; angelita@ufla.br

${ }^{4}$ Doutorando em agroquímica, pela Universidade Federal de Lavras. E-mail: andersonbsufla@yahoo.com.br.

${ }^{5}$ Doutoranda em agroquímica, pela Universidade Federal de Lavras. E-mail: claumsantos@yahoo.com.br.
} 


\section{INTRODUÇÃO}

A goiabeira é uma árvore frutífera pertencente à família Myrtácea, de ocorrência espontânea em grande parte do Brasil. Seus frutos são de coloração amarela quando maduros com cerca de $5 \mathrm{~cm}$ de diâmetro, e seu mesocarpo, de coloração rosa, contém inúmeras sementes (GUTIÉRREZ et al., 2008). Na região de Lavras (MG), as cultivares mais encontradas são Paluma, Pedro Sato e Século XXI, sendo que apenas a cultivar Pedro Sato é destinada ao consumo in natura, e as demais são destinadas ao processamento.

As substâncias ativas presentes em frutos são capazes de atuar na prevenção de várias doenças. Dentre as propriedades biológicas dessas substâncias, destacam-se sua ação antioxidante, antiplaquetária, anti-inflamatória, hipertensiva e hipoglicemiante (GUTIÉRREZ et al., 2008).

Essas propriedades têm sido atribuídas à presença de fibras alimentares, minerais e fitoquímicos com ação antioxidante, dentre os quais se destacam os compostos fenólicos, vitamina $\mathrm{C}$ e betacaroteno. Tais compostos atuam sequestrando as espécies reativas de oxigênio e complexando/quelando os íons metálicos (MELO et al., 2008; RETO et al., 2008).

A procura, cada vez maior, por melhor qualidade de vida faz com que as pessoas associem os alimentos tanto pelo seu valor nutricional quanto pelo seu valor terapêutico. O objetivo deste trabalho foi avaliar alguns compostos da goiaba que tenham efeitos benéficos para a saúde humana, em três diferentes cultivares da região de Lavras-MG.

\section{MATERIAIS E MÉTODOS}

As goiabas das cultivares Paluma, Pedro Sato e Século XXI foram adquiridas em pomar comercial da cidade de Lavras-MG. Em seguida, foram levadas ao Laboratório de Bioquímica da Universidade Federal de Lavras. Foram selecionados 35 frutos de cada cultivar, levando-se em consideração o grau de maturação, excluindo-se os frutos maduros e os muito verdes. Os frutos foram lavados, picados, congelados em nitrogênio líquido, liofilizados e, posteriormente, triturados em moinho para a obtenção das farinhas dos frutos.

Utilizou-se o delineamento experimental inteiramente casualizado (DIC), com três tratamentos, 7 repetições com 5 frutos cada. Os resultados foram submetidos à análise de variância, por meio do programa Sisvar versão 4.0 As médias foram comparadas entre si pelo teste de Tukey, a $5 \%$ de significância.

\section{Determinação da vitamina C}

O teor de vitamina $\mathrm{C}$ foi determinado pelo método colorimétrico descrito por Strohecker e Henning (1967). A vitamina C foi extraída com ácido oxálico sob agitação e, após filtração, foi dosada no extrato, empregando-se o 2,4-dinitrofenilhidrazina e usando-se o ácido ascórbico como padrão.

\section{Determinação do betacaroteno}

As amostras foram homogeneizadas com uma mistura de acetona e hexano (4:6). Os extratos obtidos foram usados para a leitura de absorbância em espectofotômetro a quatro comprimentos de onda: 435; 505; 645 e 663 nm (NAGATA; YAMASHITA, 1992).

Os cálculos das concentrações de $\beta$-caroteno foram realizados utilizando-se da seguinte equação:

B-curoveno $(\mathrm{mg} / 100 \mathrm{~mL})=0,216 \mathrm{~A} 633 \cdot 1,22, A 645 \cdot 0,304 A 505+0,452, A 45$

\section{Determinação da fibra alimentar}

Os teores de fibra alimentar total, fibra alimentar solúvel e fibra alimentar insolúvel foram determinados utilizando-se do kit dietary fiber total, marca Sigma, seguindo as técnicas propostas pela AOAC (2000). Esse método baseia- se na porção não hidrolisada do alimento que resiste à digestão enzimática sequencial com $\alpha$-amilase, protease e amiloglicosidase e é insolúvel em etanol entre 78\% e $98 \%$. Os resultados foram expressos em g. $100 \mathrm{~g}^{-1}$.

\section{Determinação dos minerais}

As amostras foram analisadas em extratos obtidos mediante a digestão nitroperclórica e leitura em espectrofotômetro de absorção atômica, conforme método descrito por Malavolta (1997).

\section{Determinação dos compostos fenólicos}

A extração dos compostos fenólicos foi realizada com metanol a $50 \%$, em refluxo por três vezes consecutivas a $80^{\circ} \mathrm{C}$ e os extratos reunidos, evaporados até $25 \mathrm{~mL}$ (GOLDSTEIN ;SWAIN,1963) e submetidos à dosagem de compostos fenólicos, utilizando-se do reagente de Folin-Denis, o qual é reduzido, pelos fenóis, a um complexo de coloração azul em solução alcalina, que é medido a $760 \mathrm{~nm}$ (AOAC, 2005). Os resultados foram expressos em $\mathrm{mg}$ de ácido tânico $\mathrm{g}^{-1} \mathrm{MS}$. 


\section{Determinação da atividade antioxidante}

Os extratos utilizados para a determinação da atividade antioxidante foram os mesmos utilizados para a determinação dos compostos fenólicos.

\section{Método DPPH}

A capacidade de sequestrar o radical 1,1-defenil-2-picrilhidrazil (DPPH) foi realizada segundo método descrito por Thaipong et al. (2006), com modificações. Foram preparadas quatro diluições dos extratos. Alíquotas de $0,1 \mathrm{~mL}$ de cada diluição foram adicionadas a 3,9 mL da solução de DPPH em metanol (0,06 mM). Ao final de 30 minutos a absorbância foi medida a $515 \mathrm{~nm}$, e a capacidade de sequestrar o radical, expressa em percentual, calculada em relação ao controle (sem antioxidante), segundo a expressão abaixo :

\section{$\%$ SEQUESTROS $=\frac{\text { Absorbăncia do controle }-}{\text { Absorbância do controle }} \times 100 \%$}

Utilizando a equação da reta, foram calculadas as concentrações necessárias para inibir 50\% do radical DPPH`. O antioxidante sintético butilhidroxitolueno (BHT) e a quercetina foram utilizados como padrão, e foram submetidos às mesmas condições.

\section{Método betacaroteno/ácido linoleico}

Para o preparo da solução sistema $\beta$-caroteno/ ácido linoleico, utilizaram-se $50 \mu \mathrm{L}$ de $\beta$-caroteno diluído em clorofórmio (20 $\mathrm{g} \mathrm{L}^{-1}$ ), aos quais adicionaram-se $40 \mu \mathrm{L}$ de ácido linoleico, $530 \mu \mathrm{L}$ de tween 20 e $1 \mathrm{~mL}$ de clorofórmio. O clorofórmio foi evaporado em rota-evaporador, e $100 \mathrm{~mL}$ de água saturada de oxigênio foram acrescentados, segundo Rufino et al. (2007), com modificações. Em tubos de ensaio, 5,0 mL dessa solução sistema foram adicionados a 0,4 mL de amostra na concentração de $0,16 \mathrm{mg} \mathrm{mL}^{-1}$. O antioxidante sintético butilhidroxitolueno (BHT) e a quercetina foram utilizados como padrão e submetidos às mesmas condições. As leituras foram realizadas em espectrofotômetro a $470 \mathrm{~nm}$. Os tubos foram colocados em banhomaria, a $40^{\circ} \mathrm{C}$, e as leituras foram realizadas antes da incubação e após 2 horas. Essas leituras foram para as amostras e para o sistema, que são os tubos sem o acréscimo de amostras.

Correlacionou-se a queda da leitura de absorbância das amostras com o sistema e estabeleceuse a porcentagem de oxidação. A percentagem de proteção contra a oxidação lipídica é dada subtraindo-se a percentagem de oxidação de cada amostra de 100.

$\%$ Oxidação $=\frac{[(\text { Redução Abs }) \text { amostra } \times 100]}{(\text { Redução Abs }) \text { sistema }}$

$\%$ Proteção $=100-(\%$ de Oxidação $)$

\section{RESULTADOS E DISCUSSÃO}

Os frutos apresentam, em sua constituição, vários compostos com ação antioxidante, os quais incluem a vitamina $\mathrm{C}, \beta$-caroteno e compostos fenólicos. A quantidade e o perfil destes fitoquímicos variam em função do tipo, cultivar e grau de maturação do vegetal bem como das condições edafoclimáticas do cultivo .

Observa-se que a cultivar Século XXI apresentou os maiores teores de compostos fenólicos e vitamina C. Evidencia-se que essa cultivar apresentou maior teor de compostos fenólicos, com polaridade semelhante ao líquido extrator (metanol 50\%).Os teores de compostos fenólicos quando transformados em matéria fresca (150,47 mg 100 g $^{-1} \mathrm{MF}$ ) ,estão de acordo com os teores encontrados por Hassimoto et al. (2005) e Melo et al. (2006), que variaram entre

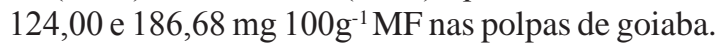

Para a vitamina C, o teor encontrado $(112,17$ mg 100 g -1 MF) foi superior ao determinado por Pereira et al. (2003), que foi de 84,90 mg $100 \mathrm{~g}^{-1} \mathrm{MF}$ em polpas de goiaba. Essa diferença no teor pode ser justificada por a vitamina $\mathrm{C}$ ser suscetível ao calor, dessecação, armazenamento e alcalinidade do meio. Não foi observada diferença significativa entre os teores de $\beta$ - caroteno para as cultivares.

A média dos teores de $\beta$ - caroteno $(0,49$ mg $100 \mathrm{~g}^{-1} \mathrm{MF}$ ) encontrada para as três cultivares estão de acordo com os dados da literatura, que variam entre 0,21 e 0,84 mg $100 \mathrm{~g}^{-1} \mathrm{MF}$ ( PORCÚ ;RODRIGUEZ, 2004; ESCOBAR; SYLOS, 2006), demonstrando que influência de variáveis agrícolas, como diferença entre cultivares, estádio de maturação, local de produção, e de processamento não interferiram no teor desse composto. A cultivar Pedro Sato apresentou os menores teores de compostos fenólicos e vitamina C.

Pelos dados apresentados na Tabela 2, observa-se que as cultivares Século XXI e Paluma apresentaram maior atividade antioxidante pelos dois métodos analisados e os maiores teores de substâncias antioxidantes.

Para efeito de comparação, utilizou-se o an- 
tioxidante sintético BHT e o flavonoide quercetina, que apresentaram o $\mathrm{IC}_{50 \%}$ de $0,015 \pm 0,00$ e 0,00198 $\pm 0,00002 \mathrm{mg} \mathrm{mL}^{-1}$, respectivamente. Em relação ao método betacaroteno/ácido linoleico a porcentagem de inibição para o BHT e quercetina foi de 74,88 $\%( \pm 0,45)$ e $60,96 \%( \pm 0,92)$, respectivamente. Os frutos das três cultivares apresentaram menores atividades antioxidantes que os padrões pelos dois métodos analisados.

Observa-se também que a cultivar Pedro Sato foi a que apresentou a menor atividade antioxidante pelos dois métodos estudados (Tabela 2) e também os menores teores dos compostos antioxidantes (Tabela 1).

Na Tabela 3, observa-se que não houve diferença significativa para os teores de fibra alimentar solúvel e insolúvel entre as cultivares. Os dados encontrados estão de acordo com os determinados por Salgado et al (1999) e Guerra et al. (2004), que encontraram um teor variando de 9,96 a 12,18 g $100 \mathrm{~g}^{-1}$ MS para a fibra insolúvel e de 1,48 a 1,58 g $100 \mathrm{~g}^{-1}$ MS para a fibra solúvel.

As fibras alimentares correspondem à parte dos frutos que são resistentes à digestão e à absorção no intestino delgado de humanos. Podem ser classificadas como alimentos funcionais, pois sua utilização pode reduzir o risco de certas doenças (dislipidemias, diabetes mellitus e doenças cardíacas). E suas ações, juntamente com as substâncias antioxidantes, previnem o desenvolvimento da aterosclerose.

A Food and Drug Administration (FDA) recomenda o consumo de $25 \mathrm{~g}$ de fibra alimentar total por dia em uma dieta de 2.000 calorias. Dessa forma, o consumo de $100 \mathrm{~g}$ de fruto in natura fornece entre 7,27 e 10,08\% da ingestão recomendada.

Os minerais: potássio, cobre e zinco não apresentaram diferenças significativas entre as cultivares analisadas. Já os teores dos minerais: ferro, magnésio e manganês foram maiores para as cultivares Paluma, Pedro Sato e Século XXI, respectivamente. Não foi detectado pelo método utilizado o teor do mineral cálcio nos frutos das três cultivares da goiabeira (Tabelas 4 e 5). Os minerais são compostos essenciais para a manutenção das funções essenciais ao organismo humano..

Os valores de IDR (Ingestão Diária Recomendada) para o potássio, magnésio, ferro, zinco, manganês e cobre são 4,6g/dia, $260 \mathrm{mg} / \mathrm{dia}, 14 \mathrm{mg} / \mathrm{dia}$, $7 \mathrm{mg} / \mathrm{dia}, 2,3 \mathrm{mg} / \mathrm{dia}$ e $900 \mu \mathrm{g} /$ dia, respectivamente, para indivíduos adultos. Dessa forma, a ingestão de $100 \mathrm{~g}$ de frutos da goiaba por dia estará fornecendo aproximadamente $0,52 \%, 0,42 \%, 0,2 \%, 0,4 \%$, $0,27 \%$ e $6,22 \%$ dos minerais: potássio, magnésio, ferro, zinco, manganês e cobre, respectivamente, o que não é muito representativo.

TABELA 1 - Teores de compostos fenólicos, betacaroteno e vitamina C para os frutos das três cultivares da goiabeira.

\begin{tabular}{|c|c|c|c|}
\hline Cultivar & $\begin{array}{c}\text { Compostos fenólicos } \\
\left(\mathrm{mg} \mathrm{g}^{-1} \mathrm{MS}\right)\end{array}$ & $\begin{array}{c}\text { Betacaroteno } \\
\left(\mathrm{mg} \mathrm{100g}^{-1} \mathrm{MS}\right)\end{array}$ & $\begin{array}{c}\text { Vitamina C } \\
\left(\mathrm{mg} \mathrm{100}^{-1} \mathrm{MS}\right)\end{array}$ \\
\hline Século XXI & $10,50 \mathrm{a}$ & $3,11 \mathrm{a}$ & $491 \mathrm{a}$ \\
\hline Paluma & $8,48 \mathrm{~b}$ & $2,88 \mathrm{a}$ & $262 \mathrm{~b}$ \\
\hline Pedro Sato & $7,45 \mathrm{c}$ & $2,75 a$ & $101,25 \mathrm{c}$ \\
\hline CV(\%) & 4,50 & 13,70 & 21,95 \\
\hline
\end{tabular}

TABELA 2- Atividade antioxidante dos frutos das três cultivares da goiabeira.

\begin{tabular}{ccc}
\hline Cultivar & DPPH $\left(\mathbf{I C}_{50 \%}\right)$ & Betacaroteno/ácido linoleico (\%) \\
\hline Século XXI & $0,369 \mathrm{a}$ & $50,52 \mathrm{a}$ \\
Paluma & $0,374 \mathrm{a}$ & $51,40 \mathrm{a}$ \\
Pedro Sato & $0,438 \mathrm{~b}$ & $39,65 \mathrm{~b}$ \\
\hline CV(\%) & 1,22 & 11,72 \\
\hline
\end{tabular}

Médias seguidas da mesma letra minúscula na coluna não diferem entre si, pelo teste de Tukey, a 5 \% de probabilidade.

TABELA 3- Teor de fibra alimentar ( $\left.100 \mathrm{~g}^{-1} \mathrm{MS}\right)$ nos frutos das três cultivares da goiabeira

\begin{tabular}{ccc}
\hline Cultivar & Fibra insolúvel & Fibra solúvel \\
\hline Século XXI & $11,12 \mathrm{a}$ & $1,48 \mathrm{a}$ \\
Paluma & $10,43 \mathrm{a}$ & $1,58 \mathrm{a}$ \\
Pedro Sato & $11,27 \mathrm{a}$ & $1,57 \mathrm{a}$ \\
\hline $\mathbf{C V}(\%)$ & 6,49 & 24,23 \\
\hline
\end{tabular}


TABELA 4- Teores médios de minerais nos frutos das três cultivares da goiabeira.

\begin{tabular}{cccc}
\hline Cultivar & Zinco $\left(\mathrm{mg} \mathrm{Kg}^{-1}\right)$ & Potássio $\left(\mathrm{g} \mathrm{Kg}^{-1}\right)$ & Cobre $\left(\mathrm{mg} \mathrm{Kg}^{-1}\right)$ \\
\hline Século XXI & $16,10 \mathrm{a}$ & $13,13 \mathrm{a}$ & $32,69 \mathrm{a}$ \\
Paluma & $19,30 \mathrm{a}$ & $14,05 \mathrm{a}$ & $34,50 \mathrm{a}$ \\
Pedro Sato & $14,35 \mathrm{a}$ & $14,53 \mathrm{a}$ & $30,87 \mathrm{a}$ \\
\hline CV(\%) & $16,32 \mathrm{a}$ & 6,23 & 7,48 \\
\hline
\end{tabular}

TABELA 5- Teores médios de minerais nos frutos das três cultivares da goiabeira

\begin{tabular}{cccc}
\hline Cultivar & Magnésio $\left(\mathrm{g} \mathrm{Kg}^{-1}\right)$ & Mangânes $\left(\mathrm{mg} \mathrm{Kg}^{-1}\right)$ & Ferro $\left(\mathrm{mg} \mathrm{Kg}^{-1}\right)$ \\
\hline Século XXI & $0,55 \mathrm{~b}$ & $5,13 \mathrm{a}$ & $11,10 \mathrm{~b}$ \\
Paluma & $0,68 \mathrm{ab}$ & $3,35 \mathrm{~b}$ & $21,25 \mathrm{a}$ \\
Pedro Sato & $0,70 \mathrm{a}$ & $2,58 \mathrm{c}$ & $15,70 \mathrm{ab}$ \\
\hline CV(\%) & 10,06 & 10,34 & 21,60 \\
\hline
\end{tabular}

Médias seguidas da mesma letra minúscula na coluna não diferem entre si, pelo teste de Tukey, a 5 \% de probabilidade.

\section{CONCLUSÕES}

1-As substâncias antioxidantes, compostos fenólicos e vitamina $C$, apresentam os maiores teores para a cultivar Século XXI. O teor de betacaroteno é semelhante para todas as cultivares analisadas.

2-As cultivares Século XXI e Paluma apresentam maior capacidade antioxidante em relação à cultivar Pedro Sato.

3-Os teores dos minerais zinco, potássio e cobre são semelhantes para as três cultivares analisadas. Já os minerais magnésio e ferro são maiores para as cultivares Paluma e Pedro Sato, e o manganês, para a Século XXI.

\section{AGRADECIMENTOS}

\section{CAPES, CNPq E FAPEMIG.}

\section{REFERÊNCIAS}

AOAC - Association Official Analytical Chemistry. Official methods of analysis of the Association of Official Analytical Chemistry. $12^{\text {th }} \mathrm{ed}$. Washington, 2000.1015p.

ESCOBAR, A. P.; SYLOS, C. M. Efeito do processo de obtenção de polpa de goiaba e goiabada sobre os teores de licopeno e betacaroteno. 2006. Dissertação (Mestrado em Análise de Alimentos) Faculdade de Ciências Farmacêuticas, Universidade Estadual Paulista, Araraquara, 2006.
GOLDSTEIN, J. L.; SWAIN, T. Changes in tannins in ripening fruits. Phytochemistry, Oxford, v. 2, p.371-383, 1963.

GUERRA, N. B.; DAVID, P. R. B. S.; MELO, D. D.; VASCONCELOS, A. B. B.; GUERRA, M. R. M. Modificação do método gravimétrico não enzimático para determinar fibra alimentar solúvel e insolúvel em frutos. Revista de Nutrição, Campinas, v. 17, n. 1, p.45-52, 2004

GUTIÉRREZ, R. M. P.; MITCHELL, S.; SOLIS, R. V. Psidium guajava : A review of its traditional uses, phytochemistry and pharmacology. Journal of Ethnopharmacology, Lausanne, v. 117, p. 1-27, 2008.

HASSIMOTO, N. M. A.; GENOVESE, M. I.; LAJOLO, F. M. Antioxidant actvity of dietary fruits, vegetables and commercial frozen fruit pulps. Journal of Agricultural and Food Chemistry, Easton,v. 53, n. 8, p. 2928-2935, 2005.

MALAVOLTA, E. Avaliação do estado nutricional das plantas. 2. ed. Piracicaba: Potafós, 1997.

MELO, E. A.; LIMA, V. L. A. G.; MACIEL, M. I. S.; CAETANO, A. C. S.; LEAL, F. L. L. Polyphenol, ascorbic acid and total carotenoid contents in common fruits and vegetables. Brazilian Journal of Food Technology, Campinas, v. 9, n.2, p. 89-94, 2006. 
MELO, E.A.;MACIEL, M.I.S.;LIMA, V.L.A.G.;NASCIMENTO,R.J. Capacidade antioxidante de frutas. Revista Brasileira de Ciências Farmacêuticas, São Paulo, v. 44, n.2, p.193-201, 2008.

NAGATA, M.; YAMASHITA, I. Simple method for simuktaneous determination of cholorophyll and carotenoids intomatoes fruits. Nippon Shokuhin Kogyo GaKKaiski, Tokyo,v.39, n.10, p.925-928, 1992.

PEREIRA, G. I. S. et al. Avaliação química da folha de cenoura visando ao seu aproveitamento na alimentação humana. Ciência e Agrotecnologia, Lavras, v. 27, n. 4, p.852-857, jul./ago. 2003.

PORCÚ, O. M.; RODRIGUEZ-AMAYA, D. B. Fatores que influenciam na composição de carotenoides em goiaba, acerola, pitanga e seus produtos processados. 2004. Dissertação (Mestrado em Química Orgânica) - Universidade Estadual de Campinas, Campinas, 2004.

RETO, M.; FIGUEIRA, M.E.; FILIPE, H.M.;ALMEIDA, C.M.M. Teor de fluoreto em infusos de chá verde (Camellia sinensis). Química Nova, São Paulo, v.31, n.2, 2008.
RUFINO, M. S. M.; ALVES, R. S.; BRITO, E. S.; MORAIS, S. M. Determinação da atividade antioxidante total em frutas pelo método betacaroteno/ ácido linoleico. Fortaleza: EMBRAPA, 2007.

SALGADO, S. M.; GUERRA, N. B.; MELO-FILHO, A. B. Polpa de fruta congelada: efeito do processamento sobre o conteúdo de fibra alimentar. Revista de Nutrição, Campinas,v. 12, n.3, p. 303308, 1999.

STROHECKER, R.; HENNING, H.M. Análises de vitaminas: métodos comprovados, Madrid: Paz Montolvo, 1967. 428 p.

THAIPONG, K. et al. Comparison of ABTS, DPPH, FRAP and ORAC assays for estimating antioxidant activity from guava fruit extracts. Journal of Food Composition and Analysis, San Diego, v. 19, n. 6/7, p.669-675, 2006. 